\title{
Epidemiological study and genetic characterization of inherited muscle diseases in a northern Spanish region
}

\author{
Inmaculada Pagola-Lorz', Esther Vicente ${ }^{2,3}$, Berta Ibáñez ${ }^{4}$, Laura Torné1 , Itsaso Elizalde-Beiras 5,6, \\ Virginia Garcia-Solaesa ${ }^{1,7}$, Fermín García $^{7}$, Josu Delfrade ${ }^{2,8}$ and Ivonne Jericó ${ }^{1,9^{*}}$ (D)
}

\begin{abstract}
Background: Inherited muscle diseases are a group of rare heterogeneous muscle conditions with great impact on quality of life, for which variable prevalence has previously been reported, probably due to case selection bias. The aim of this study is to estimate the overall and selective prevalence rates of inherited muscle diseases in a northern Spanish region and to describe their demographic and genetic features. Retrospective identification of patients with inherited muscle diseases between 2000 and 2015 from multiple data sources. Demographic and molecular data were registered.

Results: On January 1, 2016, the overall prevalence of inherited muscle diseases was 59.00/ 100,000 inhabitants (Cl 95\%; 53.35-65.26). Prevalence was significantly greater in men $(67.33 / 100,000)$ in comparison to women $(50.80 / 100$, 000) $(p=0.006)$. The highest value was seen in the age range between 45 and $54(91.32 / 100,000)$ years. Myotonic dystrophy type 1 was the most common condition (35.90/100,000), followed by facioscapulohumeral muscular dystrophy $(5.15 / 100,000)$ and limb-girdle muscular dystrophy type 2A $(2.5 / 100,000)$.

Conclusions: Prevalence of inherited muscle diseases in Navarre is high in comparison with the data reported for other geographical regions. Standard procedures and analyses of multiple data sources are needed for epidemiological studies of this heterogeneous group of diseases.
\end{abstract}

Keywords: Inherited muscle diseases, Epidemiology, Prevalence, Neuromuscular

\section{Background}

Inherited muscle diseases (IMDs), defined as rare diseases due to their low prevalence, make up a complex group of clinically and genetically heterogeneous conditions. IMDs can appear at any age and are characterized by a variety of symptoms including progressive muscle weakness, cramps, stiffness, joint deformities, chronic pain, respiratory and/or cardiac involvement, and a broad range of cognitive impairments $[1,2]$. These pathologies cause variable degrees of disability in patients and have a major impact on the quality of life and health budgets worldwide [3]. The number of subjects with this

\footnotetext{
*Correspondence: ijericop@cfnavarra.es

'Department of Neurology, Complejo Hospitalario de Navarra, IdiSNA

(Navarre Institute for Health Research), Pamplona, Spain

${ }^{9}$ Department of Neurology, Complejo Hospitalario de Navarra, 31008

Pamplona, C/ Irunlarrea, Spain

Full list of author information is available at the end of the article
}

type of condition is expected to increase due to better prevention of complications and genetic diagnosis advances, thus, prevalence data are essential for future budget estimates.

Despite the relevance of identifying these data only few epidemiological studies include all types of IMDs, and their methodology and results vary widely [4-14]. There seems to be regional differences concerning the prevalence of these conditions and potential ethnic differences are not fully understood.

For comparison purposes, standardized procedures for conducting epidemiological studies in this field have been proposed [15]. In Spain, there is little published information about IMDs. Most studies have been performed at regional level, focusing on a certain type of IMD and with wide regional variations [16-19]. The aim of our study is to describe the demographic and genetic 
features of this group of neuromuscular diseases in $\mathrm{Na}$ varre for a 16-year period (2000-2015) and to estimate the prevalence according to IMD subtype, age group and geographical distribution.

\section{Patients and methods}

Observational retrospective study based on the identification of adults and children with IMDs using all health databases available within the regional health system (from January 1, 2000 to December 31, 2015). The Navarre Ethics Research Committee approved this study. The procedures followed are in accordance with the Helsinki Declaration of 1975, as revised in 2000.

\section{Study population}

The study was conducted on a well-defined population from the Navarre Community in Northern Spain (Fig. 1) with an estimated population of 640,647 inhabitants as per the 2016 census [20]. Most citizens are covered by the Regional Public Health Service of Navarre - Osasunbidea, part of the Spanish National Health Service. Only $3.1 \%$ of the population has private o mixed health insurance [21]. Navarre is organized in seven geographic areas (Fig. 1) (Navarre 2000 Zoning) [22].

\section{Diagnostic criteria}

The study considered patients of any age, residents in Navarre during 2000-2015, with a definitive diagnosis or with high suspicion of suffering an IMD even without confirmed genetic diagnosis. We distinguished two groups of patients: 1) The definitive diagnosis of IMD group included subjects with genetically confirmed diagnosis as proposed in the 2017 version of the gene table of monogenic neuromuscular disorders [23] or with typical clinical phenotype consistent with a pathogenic mutation verified within the pedigree or patients with specific and well-correlated histopathological findings even in the absence of genetic confirmation. 2) The unclassified IMD group included patients with suspected but undiagnosed genetic muscle disease according to the phenotypes described by Harris et al. [24] following a thorough analysis of the patient: a) congenital onset and normal or mildly elevated creatine kinase (CK) levels; b) adult onset proximal weakness with significantly elevated $\mathrm{CK}$ and possible recessive inheritance; c) myopathy with prominent contractures. Patients from the second group did not meet the criteria of definitive IMD subtype as shown in Table 1. Subjects with muscle channelopathy, mitochondrial myopathies, female carriers of dystrophinopathy or isolated hyperCKemia were excluded from this study.

\section{Genetic analysis}

Blood was collected from patient after obtaining informed consent. DNA was extracted using standard procedures from peripheral blood samples taken from all patients. Appropriate genetic studies were performed in each case.

Sequencing techniques after amplification of all coding exons and adjacent areas of different genes associated to inherited muscle disease (CAPN3, DYSF, SGCG, SGCA, FKRP, ANO5, PABPN1, EMD, LMNA, GMPPB, GAA,

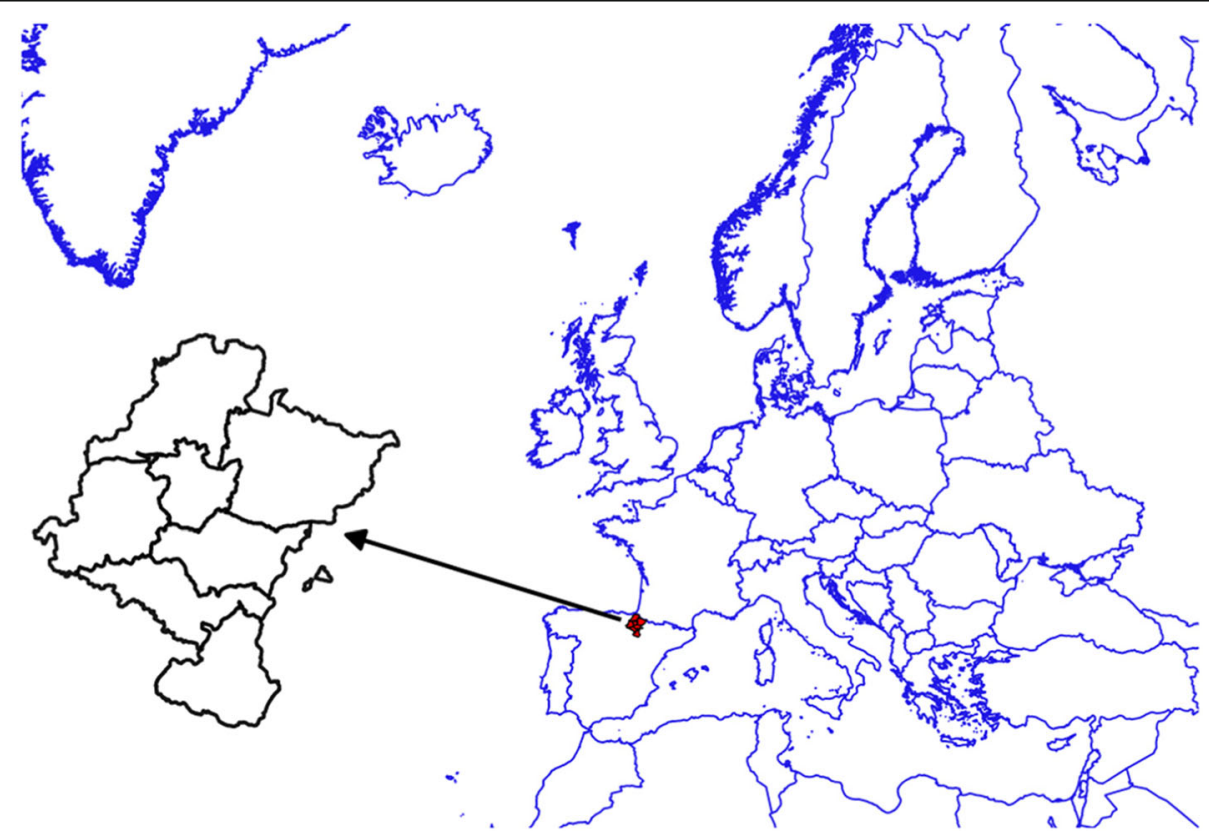

Fig. 1 Navarre is a region in northern Spain organized in seven geographic areas 
Table 1 Diagnostic criteria used for each Inherited Muscle Disease in our study

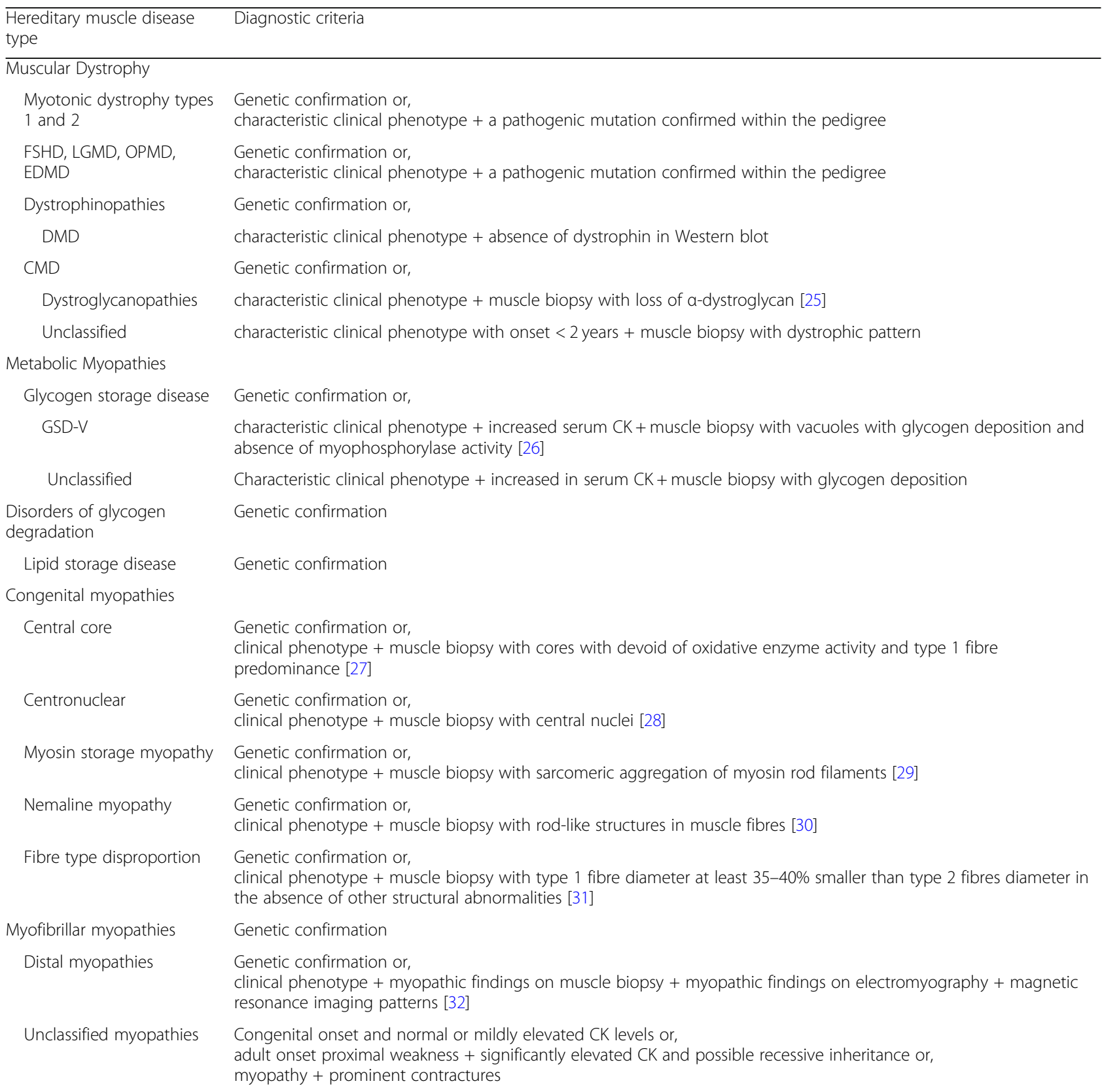

FSHD Facioscapulohumeral muscular dystrophy, LGMD Limg girdle muscular dystrophy, OPMD Oculopharyngeal muscular dystrophy, EDMD Emery-Dreifuss muscular dystrophy, DMD Duchenne muscular dystrophinopathy, CMD Congenital muscular dystrophy

PYGM, CPT2, MYH-7, ACTA1, LDB3) were performed to determine the DNA variants consistent in base changes; substitutions, and small insertions and deletions. First studies were carried out by Sanger sequencing following diagnostic algorithms gene-to-gene, while the implementation of the next generation sequencing (NGS) techniques in clinical diagnosis was studied by groups or panels in different NGS platforms. Bioinformatic tools were used to the alignment of the sequences to human reference genome; and detection, annotation and prioritization of variants.

$D M D$ gene dosage analysis was determined by multiplex ligation-dependent probe amplification (MLPA). The SALSA ${ }^{\bullet}$ MLPA $^{\oplus}$ P034 DMD-1 and P035 DMD-2 (MRC-Holland, Amsterdam) were used for the detection of exon deletions or duplications in the DMD gene while point mutations were identified by sequencing studies. 
Myotonic dystrophy type 1 (DM-1) is caused by (CTG)n repeat expansion in the 3 '-untranslated region of the $D M P K$ gene. The sizing of this expansion was done by conventional PCR, fragment-length analysis, repeat-primed PCR, and fragment-length analysis.

The contraction of the D4Z4 repeat on chromosomes 4 is responsible of the facioscapulohumeral muscular dystrophy type 1 (FSHD1). The size of the D4Z4 repeats was determined by pulsed field gel electrophoresis (PFGE) as previously described [33]. Facioscapulohumeral muscular dystrophy type 2 (FSHD2) was studied by sequencing of $S M C H D 1$ gene, which is involved in the maintenance of D4Z4 methylation.

Variants of interest detected by sequencing were classified according to different databases and the published literature. Population databases: 1000 Genomes Project (http://browser.1000genomes.org), Exome Variant Server (http://evs.gs.washington.edu/EVS) and Exome Aggregation Consortium (http://exac.broadinstitute.org/). Disease databases: Human Gene Mutation Database (http://www. hgmd.org), Leiden Open Variation Database (http://www. lovd.nl) and ClinVar (http://www.ncbi.nlm.nih.gov/clinvar). In silico approach was carried out to assess the pathogenicity of new variants using different tools as $\mathrm{Mu}-$ tation Taster (http://www.mutationtaster.org).

Methodological validation and segregation studies were performed by direct sequencing (ABI 3500 Genetic Analyzer, Applied Biosystems, Warrington, UK) using Big Dye Terminator Cycle Sequencing Kit (Applied Biosystems, Warrington, UK). The subsequent analysis was done with SeqScape software (Thermo Fisher).

\section{Case ascertainment sources}

Case ascertainment was achieved using multiple overlapping sources:

(1) Navarre's Minimum Basic Data Set (MBDS), a regional computer-based database system designed to collect demographic, clinical and administrative data on discharges, including both private and publicly funded hospitals. International Classification of Diseases (Ninth Revision, Clinical Modification, ICD-9-CM), including 271.0, 272.7, 359.0, 359.1, 359.2, 359.21, 359.22, 359.29, 359.89 and 359.9, were used to search patients affected by IMDs [34].

(2) Electronic Clinical Records in Primary Care (ECRPC) of Navarres Public Health System, a regional healthcare information system that allows registering demographic, clinical and administrative data on primary care episodes. International Classification of Primary Care, second edition (ICPC-2) was used to encode healthcare episodes [35]. In Navarre, the ECRPC system proposes several literal descriptors linked to the ICPC-2 codes for general practitioners, including muscular dystrophy and unspecified myopathy for code N99 (Neurological disease, other), which we used for selecting the patients [36].
(3) Temporary Occupational Disability Registry of Navarre, designed to collect data on sick leaves. ICD-9-CM codes, including the aforementioned ones, were used to select patients affected by IMDs [36].

(4) Records from the Medical Genetics Service allowed selecting patients that were being monitored for IMD suspicion. Several keywords enabled us to detect these patients, depending on the reason for the request of the genetic study.

(5) The Congenital Anomalies and Hereditary Diseases Registry of Navarre, a population-based listing affiliated member to EUROCAT [37]. Keyword diagnostic searches were used to select patients suffering IMDs.

(6) Navarre's Mortality Statistics in which the primary cause of death from the Medical Death Certificate [38, 39 ] is listed. We used the ICD-10 codes, including G71.0, G71.1, G71.2, G71.3, G71.8, G71.9, G72.8, G72.9 and G73.6 to identify IMD patients.

(7) Electronic Clinical Records from the Neurology Services of Navarre's public hospitals. Patients with IMDs were detected using keyword diagnostic searches.

The information from the various data sources showed all potential diagnoses of IMDs. This information was cross-checked with the databases for duplication. Next, a neuromuscular neurologist verified the diagnosis of each double-checked case based on the inclusion and exclusion criteria for each condition.

We collected the following information: type of IMD, gender, date of birth, date of death, place of residence on January 1, 2016, and genetic diagnosis.

\section{Data analysis}

January 1, 2016 was the date chosen for estimating prevalence. The population at risk is defined as the residents of Navarre as per the Spanish National Statistics Institute and the Statistics Institute of Navarre [20] (Navarre population $=640,647$ ). The 2016 prevalence rates are expressed as cases/100,000 inhabitants. An overall prevalence was estimated globally and by gender, age and geographical area within Navarre. Descriptive results are presented as frequencies and proportions. Poisson distribution was assumed to estimate CI 95\% for prevalence and proportions rates. For inter-group proportion comparisons, the Pearson Chi-square test was applied. Statistical analyses were conducted using the OpenEpi program [40].

\section{Results}

The search strategy allowed us to retrieve 2729 potential cases after the removal of duplicates, from which 1899 required diagnostic verification (Fig. 2). Five hundred thirteen cases fulfilled the diagnostic standards listed in Table 1, representing $27.01 \%$ of the initial potential cases: 281 (54.77\%) males and $232(45.22 \%)$ females 


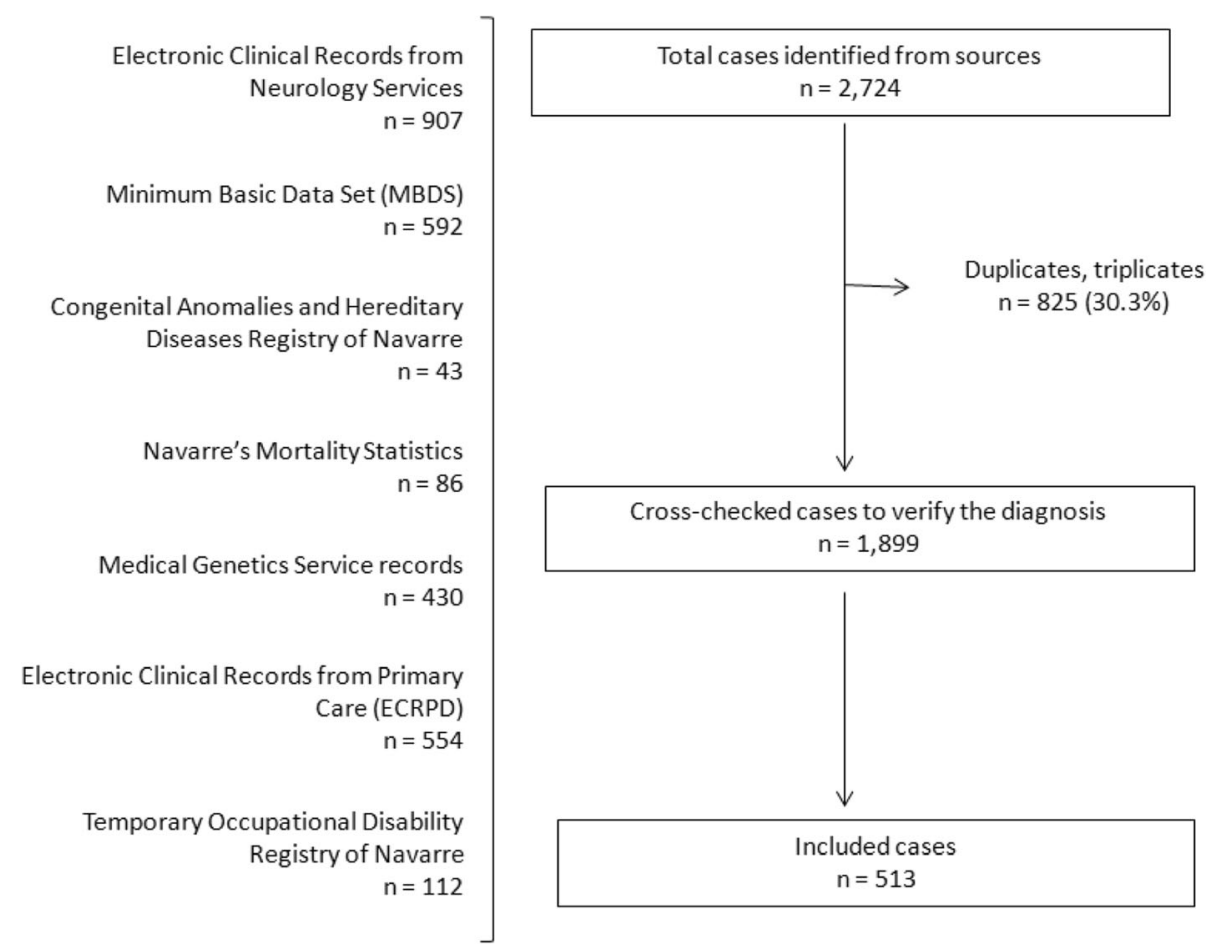

Fig. 2 Flow-chart of potential cases of inherited muscle disease in Navarre, 2000-2015

(1.21:1). Twenty-six different disease entities were detected. During the study period, $23.20 \%$ of the subjects (62 males and 57 females) died.

\section{Genetic and other diagnostic standards}

From the 513 identified IMDs, 464 were definitive and 49 unclassified IMDs, respectively. Concerning the definitive IMD cases, 329 (70.90\%) were genetically verified, $113(24.35 \%)$ had a clinical phenotype with a pathogenic mutation confirmed with the pedigree, and in $22(4.74 \%)$, characteristic muscle biopsy pathogenic features were found (Table 2).

Genetic descriptions of dystrophinopathies are detailed in Table 3, while the rest of IMDs can be seen Table 4 .

\section{Prevalence}

On 1 January 2016, 378 subjects with IMDs (56.61\% male and $43.39 \%$ female) were residents of Navarre, implying a prevalence of 59.00/100,000 inhabitants (CI 95\%; 53.35-65.26) (Table 5). DM-1 represented the most common IMDs, with a prevalence of $35.90 / 100,000$ (CI 95\%; 31.55-40.85), followed by facioscapulohumeral muscular dystrophy (FSHD) and limb girdle muscular dystrophy 2A (LGMD2A) affecting 5.15/100,000 (95\% CI; 3.67-7.23) and 2.5/100,000 (CI 95\%; 1.54-4.05) inhabitants, respectively. There were 11 cases of dystrophinopathies, with Duchenne muscular dystrophy (DMD) present in 0.94/100,000 (CI 95\%; 0.43-2.04) and Becker muscular dystrophy (BMD) in 0.78/100,000 (CI 95\%; 0.33-1.83) individuals. Congenital myopathy, congenital muscular dystrophy (CMD), myofibrillar myopathy, and metabolic myopathy were observed in 1.25 (CI 95\%; 0.63-2.46), 0.62 (CI 95\%; 0.24-1.60), 0.78 (CI 95\%; $0.33-1.83$ ), and 1.71 (CI 95\%; 0.95-3.07) per every 100 , 000 inhabitants, respectively.

The range of age was $1-89$ years, with a mean age of 46.93 years (SD 17.77) (45.70 (SD 19.01) for males and 48.54 (SD 15.93) for females). The highest age-specific prevalence (Table 6) was obtained for the age range between 45 to 54 years, with a prevalence of 91.32/100,000 (CI 95\%; 74.31-112.2) subjects. Prevalence was statistically significant higher in males in comparison to females for the following groups: under 15, 25 to 34, and 75 to 84 years of age.

The prevalence of IMDs differed notably by geographic areas, with the highest estimate found for the region of Tierra Estella (97.15/100,000 subjects), significantly higher in comparison to all other areas, except for the Eastern Middle area of Navarre. Figure 3 shows the geographical distribution of IMD prevalence.

\section{Discussion}

In this study, we present data on Inherited Muscle Diseases compiled over a 16-year period from different healthcare information systems. Our results show a prevalence of IMDs in Navarre of 59.00/100,000 subjects, being higher in males than in females, highest for 
Table 2 Inherited Muscle Disease subtype and diagnostic standard used

\begin{tabular}{|c|c|c|}
\hline HM Type & Diagnostic standard & $\mathrm{N}^{\circ}$ of cases \\
\hline \multirow[t]{2}{*}{$\overline{\mathrm{DM}}-1$} & Genetic confirmation & 225 \\
\hline & Clinical phenotype + pedigree & 97 \\
\hline \multirow[t]{2}{*}{ FSHD } & Genetic confirmation & 32 \\
\hline & Clinical phenotype + pedigree & 9 \\
\hline \multirow[t]{2}{*}{ LGMD2 } & Genetic confirmation & 27 \\
\hline & Clinical phenotype + pedigree & 4 \\
\hline LGMD2C & Clinical phenotype + muscle biopsy & 2 \\
\hline OPMD & Genetic confirmation & 5 \\
\hline EDMD & Genetic confirmation & 5 \\
\hline \multirow[t]{2}{*}{ DMD } & Genetic confirmation & 13 \\
\hline & Clinical phenotype + muscle biopsy & 2 \\
\hline BMD & Genetic confirmation & 7 \\
\hline \multirow[t]{3}{*}{ Dystroglycanopathies } & Genetic confirmation & 1 \\
\hline & Clinical phenotype + pedigree & 1 \\
\hline & Clinical phenotype + muscle biopsy & 1 \\
\hline Unclassified CMD & Clinical phenotype + muscle biopsy & 2 \\
\hline GSD-॥ & Genetic confirmation & 2 \\
\hline \multirow[t]{2}{*}{ GSD-V } & Genetic confirmation & 4 \\
\hline & Clinical phenotype + muscle biopsy & 2 \\
\hline Unclassified GSD & Clinical phenotype + muscle biopsy & 2 \\
\hline Lipid storage disease & Genetic confirmation & 1 \\
\hline Central Core & Clinical phenotype + muscle biopsy & 2 \\
\hline \multirow[t]{2}{*}{ Myosin storage myopathy } & Genetic confirmation & 2 \\
\hline & Clinical phenotype + muscle biopsy & 1 \\
\hline \multirow[t]{2}{*}{ Nemaline myopathy } & Genetic confirmation & 1 \\
\hline & Clinical phenotype + muscle biopsy & 2 \\
\hline Fibre type disproportion & Clinical phenotype + muscle biopsy & 3 \\
\hline \multirow[t]{2}{*}{ Zaspopathy } & Genetic confirmation & 4 \\
\hline & Clinical phenotype + pedigree & 2 \\
\hline Distal myopathies & Clinical phenotype + magnetic resonance imaging patterns & 3 \\
\hline
\end{tabular}

DM-1 Myotonic dystrophy type 1, FSHD Facioscapulohumeral muscular dystrophy, LGMD Limb girdle muscular dystrophy, OPMD Oculopharyngeal muscular dystrophy, EDMD Emery-Dreifuss muscular dystrophy, DMD Duchenne muscular dystrophinopathy, CMD congenital muscular dystrophy, BMD Becker muscular dystrophinopathy, CMD Congenital muscle dystrophy, GSD Glycogen storage disease.

the 45 to 54 years age range, and with remarkable geographical variability. DM-1, FSHD, and LGMD2A are the most common subtypes IMDs.

We believe the non-inclusion in the analyses of the unclassified group of IMDs may underestimate the real prevalence, bearing in mind that each case was thoroughly assessed by a specialized neurologist. To avoid selection biases when comparing with other studies, we also present prevalence with a confirmed genetic diagnosis: 50.10/100,000 (CI 95\%; 44.92-55.89), which remains to be high in comparison to the results published elsewhere [5]. Four hundred and forty two cases $(86.16 \%)$ of IMDs had a confirmed genetic diagnosis.

\section{Epidemiological studies of neuromuscular diseases}

Prevalence studies require exhaustiveness. The lack of specific registries and the absence of diagnostic code verifications [9, 41-43] could lead an IMD selection bias [15]. Moreover, for comparability purposes stringent inclusion criteria is mandatory.

Aiming to avoid these intrinsic limitations in prevalence studies, for this study we used seven case 
Table 3 Genetically confirmed dystrophinopathies

\begin{tabular}{|c|c|c|c|c|}
\hline Case number & Dystrophinopathy type & Gene & Mutation type & Position and/or sequence variation \\
\hline 1 & DMD & $D M D$ & Deletion & Exons 44-55 \\
\hline 2 & DMD & $D M D$ & Deletion & Exons $18-28$ \\
\hline 3 & DMD & DMD & Duplication & Exons $18-48$ \\
\hline 4 & DMD & DMD & Deletion & Exons 49 y 50 \\
\hline 5 & DMD & $D M D$ & Deletion & Exons $45-53$ \\
\hline 6 & DMD & DMD & Deletion & Exons $45-49$ \\
\hline 7 & DMD & $D M D$ & Duplication & Exon 3 \\
\hline 8 & DMD & DMD & SNV & c.353G > A, p.Trp118 \\
\hline 9 & DMD & $D M D$ & Deletion & Exon 43 \\
\hline 10 & DMD & $D M D$ & Deletion & Exons $44-50$ \\
\hline $11^{\mathrm{a}}$ & DMD & & & \\
\hline $12^{\mathrm{a}}$ & DMD & & & \\
\hline $13^{b}$ & DMD & & & \\
\hline 14 & BMD & $D M D$ & Deletion & Exon 52 \\
\hline 15 & BMD & $D M D$ & Deletion & Intron 49 \\
\hline 16 & BMD & $D M D$ & Deletion & Exons 3-7 \\
\hline 17 & BMD & $D M D$ & Deletion & Exons 45-55 \\
\hline 18 & BMD & $D M D$ & Duplication & Exon 2 \\
\hline $19^{b}$ & BMD & & & \\
\hline $20^{b}$ & BMD & & & \\
\hline
\end{tabular}

${ }^{a}$ No mutation identified. Negative deletion/duplication study. Positive familial segregation

${ }^{\mathrm{b}}$ Evidence of genetic confirmation in the clinical record; no access to the identified mutation

ascertainment sources at different healthcare levels and made an exhaustive verification of the diagnoses with well-defined inclusion and exclusion criteria.

\section{Data sources}

This study was affected by the lack of disease codification specificity in the Spanish healthcare information systems for IMDs. Only $27.01 \%$ of the cases initially identified with the selected codes and keywords met the inclusion criteria for IMD. Thus, it is essential to review and verify the diagnosis procedures to obtain quality data for this type of epidemiological.

The introduction of population-based registries specific for neuromuscular and/or other rare diseases, including specific codes, would be of great help in future studies.

\section{Overall and disease-specific prevalence data}

Our study shows a prevalence of IMDs of 59.00/100,000 (CI 95\%; 53.35-65.26) inhabitants for Navarre. Comparisons with prevalence data from other regions is complicated due to the lack of methodological homogeneity and because most studies focus on a specific IMD. Emery [44] reports a global prevalence of hereditary neuromuscular disorders of 1/3500 inhabitants (prevalence 28.57/100,000), including spinal muscular atrophy and hereditary sensitive-motor neuropathy. In another study carried out in the UK, a prevalence of IMDs of 37/100,000 people is described for a Northern region of England [6]. More recently, Theadom et al. [5] describe a prevalence of 22.3/100,000 inhabitants of all genetic muscle disorders in New Zealand, with higher incidence in subjects of European ancestry.

To the best of our knowledge, this is the first time a study includes all types of IMDs in a Spanish region.

The subtype of IMD with the highest number of cases in our series was DM-1 (58.87\% of the cases) with a prevalence of 35.90/100,000 (CI 95\%; 31.55-40.85). In previous works, the prevalence of this particular condition showed wide geographical variations. The lowest reported for Japan $(0.2 / 100,000)$ [8] up to $172 / 100,000$ for Quebec [45] due to the founder effect. Regarding data from Spanish regions, Burcet et al. [18] found 10.9/100, 000 cases of DM-1 in Majorca, while Munain et al. [16] reported 26.5/100,000 in Guipuzcoa. These regional variations could indicate a possible underestimation of prevalence linked to the used methodology.

However, we believe that despite the used methodology, the high prevalence of DM-1 in Navarre could be explained by a possible founding effect, similar to that reported for Guipuzcoa [16], considering that both 
Table 4 Pathogenic molecular defect of each genetically confirmed IMD

\begin{tabular}{|c|c|c|c|c|c|c|c|}
\hline Muscular disease type & Gene & Mutation type & Sequence variation & Position & Zygosity & Cases, $\mathrm{n}$ & Families, $n$ \\
\hline \multicolumn{8}{|l|}{ Muscular dystrophy } \\
\hline MD1 & DMPK & Expanded CTG (> 40) & & 3'-UTR & & 225 & 116 \\
\hline FSHD1 & DUX & Deletion D4Z4 & & & & 25 & 21 \\
\hline \multirow[t]{2}{*}{ FSHD2 } & SMCHD1 & SNV & c. $5602 C>T$ & Exon 45 & Het & 6 & 1 \\
\hline & SMCHD1 & SNV & c. $2329 \mathrm{~A}>\mathrm{T}$ & Exon 18 & Het & 1 & 1 \\
\hline \multirow[t]{2}{*}{ LGMD2A } & CAPN3 & Frameshift variant & c.2362_2363delinsAG/TCATCT & Exon 22 & Hom & 16 & 15 \\
\hline & $\begin{array}{l}\text { CAPN3 } \\
\text { CAPN3 }\end{array}$ & $\begin{array}{l}\text { SNV } \\
\text { Frameshift variant }\end{array}$ & $\begin{array}{l}\text { c.664G > A } \\
\text { c.2362_2363delinsAG/TCATCT }\end{array}$ & $\begin{array}{l}\text { Exon } 5 \\
\text { Exon } 22\end{array}$ & $\begin{array}{l}\text { Het } \\
\text { Het }\end{array}$ & 1 & 1 \\
\hline LGMD2B & DYSF & SNV & c. $895 G>A$ & Exon 9 & Hom & 1 & 1 \\
\hline LGMD2C & SGCG & SNV & $c .848 \mathrm{G}>\mathrm{A}$ & Exon 8 & Hom & 2 & 2 \\
\hline LGMD2D & SGCA & SNV & c. $293 G>A$ & Exon 3 & Hom & 1 & 1 \\
\hline LGMD2I & FKRP & SNV & C. $826 C>A$ & Exon 4 & Hom & 1 & 1 \\
\hline \multirow[t]{4}{*}{ LGMD2L } & ANO5 & Frameshift variant & c.1627dupA & Exon 15 & Hom & 1 & 1 \\
\hline & ANO5 & Frameshift variant & c.191dupA & Exon 5 & Hom & 2 & 1 \\
\hline & $\begin{array}{l}\text { ANO5 } \\
\text { ANO5 }\end{array}$ & $\begin{array}{l}\text { Frameshift variant } \\
\text { SNV }\end{array}$ & $\begin{array}{l}\text { c.191dupA } \\
\text { c.1664G > T }\end{array}$ & $\begin{array}{l}\text { Exon } 5 \\
\text { Exon } 16\end{array}$ & $\begin{array}{l}\text { Het } \\
\text { Het }\end{array}$ & 1 & 1 \\
\hline & $\begin{array}{l}\text { ANO5 } \\
\text { ANO5 }\end{array}$ & $\begin{array}{l}\text { SNV } \\
\text { Splice variant }\end{array}$ & $\begin{array}{l}\text { C. } 172 C>T \\
\text { C. } 1119+1 G>T\end{array}$ & $\begin{array}{l}\text { Exon } 4 \\
\text { Intron } 12\end{array}$ & $\begin{array}{l}\text { Het } \\
\text { Het }\end{array}$ & 1 & 1 \\
\hline OPMD & PABPN1 & Expanded GCN (> 10) & & Exon 1 & & 5 & 4 \\
\hline Emerin EDMD & EMD & Complete deletion & & & & 1 & 1 \\
\hline \multirow[t]{3}{*}{ Lamin EDMD } & LMNA & SNV & c. $1130 \mathrm{G}>\mathrm{A}$ & Exon 6 & Het & 2 & 1 \\
\hline & LMNA & SNV & $c .215 G>T$ & Exon 1 & Het & 1 & 1 \\
\hline & LMNA & SNV & c. $65 C>A$ & Exon 1 & Het & 1 & 1 \\
\hline DMC-Dystroglicanopathy & GMPPB & SNV & $c .553 C>T$ & Exon 5 & Hom & 1 & 1 \\
\hline \multicolumn{8}{|l|}{ Metabolic myopathy } \\
\hline \multirow[t]{2}{*}{ GSD-II } & $\begin{array}{l}\text { GAA } \\
\text { GAA }\end{array}$ & $\begin{array}{l}\text { Intronic variant } \\
\text { SNV }\end{array}$ & $\begin{array}{l}\text { c. }-32-13 T>G \\
\text { c. } 1933 G>T\end{array}$ & $\begin{array}{l}\text { Intron } 1 \\
\text { Exon } 14\end{array}$ & $\begin{array}{l}\text { Het } \\
\text { Het }\end{array}$ & 1 & 1 \\
\hline & $\begin{array}{l}\text { GAA } \\
\text { GAA }\end{array}$ & $\begin{array}{l}\text { Intronic variant } \\
\text { SNV }\end{array}$ & $\begin{array}{l}\text { c. }-32-13 T>G \\
\text { c. } 1724 A>G\end{array}$ & $\begin{array}{l}\text { Intron } 1 \\
\text { Exon } 12\end{array}$ & $\begin{array}{l}\text { Het } \\
\text { Het }\end{array}$ & 1 & 1 \\
\hline \multirow[t]{4}{*}{ GSD-V } & PYGM & Stop gained & c. $148 \mathrm{C}>\mathrm{T}$ & Exon 1 & Hom & 1 & 1 \\
\hline & $\begin{array}{l}\text { PYGM } \\
\text { PYGM }\end{array}$ & $\begin{array}{l}\text { Stop gained } \\
\text { SNV }\end{array}$ & $\begin{array}{l}\text { c. } 148 C>T \\
\text { c. } 1468 C>T\end{array}$ & $\begin{array}{l}\text { Exon } 1 \\
\text { Exon } 12\end{array}$ & $\begin{array}{l}\text { Het } \\
\text { Het }\end{array}$ & 1 & 1 \\
\hline & PYGM ${ }^{a}$ & & & & & 1 & 1 \\
\hline & PYGM ${ }^{a}$ & & & & & 1 & 1 \\
\hline Lipid storage disease & CPT2 & $\begin{array}{l}\text { SNV } \\
\text { SNV }\end{array}$ & $\begin{array}{l}\text { C. } 359 A>G \\
\text { c. } 1547 T>C\end{array}$ & $\begin{array}{l}\text { Exon } 4 \\
\text { Exon } 4\end{array}$ & $\begin{array}{l}\text { Het } \\
\text { Het }\end{array}$ & 1 & 1 \\
\hline \multicolumn{8}{|l|}{ Congenital myopathy } \\
\hline \multirow[t]{2}{*}{ Myosin storage } & MYH-7 & SNV & c. $5533 \mathrm{C}>\mathrm{T}$ & Exon 37 & Het & 1 & 1 \\
\hline & MYH-7 & SNV & c.1314G > A & Exon 14 & Het & 1 & 1 \\
\hline Nemaline & ACTA1 & SNV & $\mathrm{c} .808 \mathrm{G}>\mathrm{C}$ & Exon 5 & Het & 1 & 1 \\
\hline \multicolumn{8}{|l|}{ Myofibrillar myopathy } \\
\hline Zaspopathy & LDB3 & SNV & c. $494 C>T$ & Exon 5 & Het & 4 & 1 \\
\hline
\end{tabular}

${ }^{a}$ Evidence of genetic confirmation in the clinical record; no access to the identified mutation Hom Homozygous, Het Heterozygous, SNV Single Nucleotide Variation 
Table 5 Inherited muscle disease prevalence in Navarre by January 1, 2016

\begin{tabular}{|c|c|c|c|c|c|c|}
\hline Type of myopathy & Cases, $n$ & $\mathrm{PR \times 10}$ (Cl 95\%) & PR male & PR female & $p$ & Mean age (SD) \\
\hline Muscular dystrophy & 312 & $48.70(43.59-54.41)$ & 53.80 & 43.67 & 0.066 & $46.43(17.14)$ \\
\hline Myotonic dystrophy 1 & 230 & $35.90(31.55-40.85)$ & 36.18 & 35.63 & 0.906 & 47.06 (15.39) \\
\hline FSHD & 33 & $5.15(3.67-7.23)$ & 6.92 & 3.41 & 0.052 & $55.51(14.44)$ \\
\hline FSHD1 & 27 & $4.21(2.90-6.13)$ & 5.98 & 2.48 & 0.320 & $58.15(13.06)$ \\
\hline FSHD2 & 6 & $0.94(0.43-2.04)$ & 0.94 & 0.93 & 0.985 & 43.67 (15.54) \\
\hline LGMD2 & 27 & $4.21(0.90-6.13)$ & 5.03 & 3.41 & 0.325 & $45.04(17.67)$ \\
\hline LGMD2A & 16 & $2.50(1.54-4.05)$ & 2.52 & 2.48 & 0.975 & $43.81(14.63)$ \\
\hline LGMD2B & 1 & $0.16(0.03-0.88)$ & 0.31 & 0.00 & 0.496 & $56(-)$ \\
\hline LGMD2C & 3 & $0.47(0.16-1.38)$ & 0.94 & 0.00 & 0.122 & $21.33(24.45)$ \\
\hline LGMD2D & 1 & $0.16(0.03-0.88)$ & 0.00 & 0.31 & 0.503 & $46(-)$ \\
\hline LGMD2I & 1 & $0.16(0.03-0.88)$ & 0.31 & 0.00 & 0.496 & $53(-)$ \\
\hline LGMD2L & 5 & $0.78(0.33-1.83)$ & 0.94 & 0.62 & 0.675 & $59.20(16.51)$ \\
\hline OPMD & 2 & $0.31(0.08-1.14)$ & 0.63 & 0.00 & 0.246 & $72(15,56)$ \\
\hline EDMD & 5 & $0.78(0.33-1.83)$ & 0.94 & 0.62 & 0.675 & $41.80(19.32)$ \\
\hline Emerin EDMD & 1 & $0.16(0.03-0.88)$ & 0.31 & 0.00 & 0.496 & $19(-)$ \\
\hline Lamin EDMD & 4 & $0.62(0.24-1.60)$ & 0.63 & 0.62 & 0.988 & $47.5(16.76)$ \\
\hline Dystrophinopathy & 11 & $1.71(0.95-3.07)$ & 3.46 & 0.00 & 0.000 & $18.73(18.26)$ \\
\hline $\mathrm{DMD}$ & 6 & $0.94(0.43-2.04)$ & 1.89 & 0.00 & 0.015 & $8.33(4.80)$ \\
\hline $\mathrm{BMD}$ & 5 & $0.78(0.33-1.83)$ & 1.57 & 0.00 & 0.030 & $31.2(21.18)$ \\
\hline CMD & 4 & $0.62(0.24-1.60)$ & 0.63 & 0.62 & 0.988 & $13.25(6.34)$ \\
\hline Glycosylation disorder & 3 & $0.47(0.16-1.38)$ & 0.63 & 0.31 & 0.616 & $10.67(4.51)$ \\
\hline Unclassified CMD & 1 & $0.16(0.03-0.88)$ & 0.00 & 0.31 & 0.503 & $21(-)$ \\
\hline Metabolic myopathies & 11 & $1.71(0.95-3.07)$ & 2.52 & 0.93 & 0.139 & 45.91 (19.13) \\
\hline Glycogen storage & 10 & $1.56(0.85-2.87)$ & 2.52 & 0.62 & 0.062 & $49.10(16.80)$ \\
\hline GSD-\| & 2 & $0.31(0.08-1.14)$ & 0.63 & 0.00 & 0.246 & $43(12.73)$ \\
\hline GSD-V & 6 & $0.94(0.43-2.04)$ & 1.26 & 0.62 & 0.442 & $5.15(20.83)$ \\
\hline Unclassified & 2 & $0.31(0.08-1.14)$ & 0.63 & 0.00 & 0.246 & $48(9.90)$ \\
\hline Lipid storage disease & 1 & $0.16(0.03-0.88)$ & 0.00 & 0.31 & 0.503 & $14(-)$ \\
\hline Congenital myopathy & 8 & $1.25(0.63-2.46)$ & 2.20 & 0.31 & 0.037 & $36.12(14.20)$ \\
\hline Central Core & 2 & $0.31(0.08-1.14)$ & 0.63 & 0.00 & 0.246 & $22.50(24.75)$ \\
\hline Myosin storage myopathy & 3 & $0.47(0.16-1.38)$ & 0.94 & 0.00 & 0.122 & $44.67(9.07)$ \\
\hline Fibre type disproportion & 3 & $0.47(0.16-1.38)$ & 0.63 & 0.31 & 0.616 & $36.67(4.62)$ \\
\hline Distal myopathy & 3 & $0.47(0.16-1.38)$ & 0.63 & 0.31 & 0.616 & $65.67(17.78)$ \\
\hline Zaspopathy & 5 & $0.78(0.33-1.83)$ & 1.26 & 0.31 & 0.212 & $63.40(4.88)$ \\
\hline Unclassified myopathy & 39 & $6.09(4.45-8.32)$ & 6.92 & 5.27 & 0.402 & $59.92(21.86)$ \\
\hline Total & 378 & $59.00(53.35-65.26)$ & 67.33 & 50.80 & 0.006 & 46.93 (17.77) \\
\hline
\end{tabular}

SD Standard deviation.

$O P M D$ Oculopharyngeal muscular dystrophy, EDMD Emery-Dreifuss muscular dystrophy, DMD Duchenne muscular dystrophinopathy, CMD Congenital muscular dystrophy, $B M D$ Becker muscular dystrophinopathy, $C M D$ congenital muscle dystrophy, GSD glycogen storage disease.

regions share cultural and background similarities. Moreover, the management of the patients by multidisciplinary teams in recent years may have a positive effect on survival by lowering the complications.

Prevalence of LGMD also differs between studies. Theadom's review [15] reports a global prevalence of
LGMD of $0.9 / 100,000$ inhabitants. Here, we show a higher prevalence of LGMD $(4.21 / 100,000)$ (CI of 95\% 2.90-6.13), closer to the $4.8 / 100,000$ estimated by Fardeu et al. [46] in a tiny community in Reunion, where high rates of endogamy have been described. In Spain, a study by Urtasun et al. in the Basque Country found a 
Table 6 Prevalence of Inherited Muscle Disease according to group age and gender

\begin{tabular}{|c|c|c|c|c|}
\hline \multirow[t]{2}{*}{$\begin{array}{l}\text { Group } \\
\text { age }\end{array}$} & \multirow[t]{2}{*}{$\begin{array}{l}\mathrm{PR} / 100,000 \\
(\mathrm{Cl} 95 \%)\end{array}$} & \multicolumn{2}{|l|}{$\begin{array}{l}\mathrm{PR} / 100,000(\mathrm{Cl} 95 \%) \\
\text { by gender }\end{array}$} & \multirow[t]{2}{*}{$p$} \\
\hline & & Women & Men & \\
\hline$<15$ & $21.87(14.44-33.11)$ & $10.20(4.36-23.87)$ & $32.97(20.59-52.80)$ & 0.015 \\
\hline $15-24$ & $41.84(28.56-61.30)$ & $42.84(25.04-73.29)$ & 40.89 (23.9-69.95) & 0.906 \\
\hline $25-34$ & 48.99 (35.39-67.82) & $21.93(11.11-43.27)$ & 75,68 (52.37-109.40) & 0.000 \\
\hline $35-44$ & $72.13(57.64-90.26)$ & 70.53 (50.95-97.62) & 73.63 (54.08-100.24) & 0.853 \\
\hline $45-54$ & $91.32(74.31-112.2)$ & 93.36 (69.79-124.92) & 89.37 (66.81-119.6) & 0.836 \\
\hline $55-64$ & 91.50 (72.56-115.40) & $82.69(58.58-116.7)$ & $100.27(73.37-137.20)$ & 0.421 \\
\hline $65-74$ & $59.40(42.92-82.23)$ & 57.51 (36.38-90.9) & 61.43 (38.86-97.09) & 0.844 \\
\hline $75-84$ & 39.08 (24.06-63.47) & $21.42(9.15-50.14)$ & $62.48(34.9-111.90)$ & 0.044 \\
\hline$\geq 85$ & 23.38 (9.99-54.73) & $13.92(3.81-50.76)$ & $42.73(14.53-125.62)$ & 0.245 \\
\hline Total & $59.00(53.35-65.26)$ & $50.80(43.46-59.36)$ & $67.33(58.9-76.97)$ & 0.006 \\
\hline
\end{tabular}

prevalence of 6.9/100,000 [17]. The most common form of LGMD is LGMD2A in the Basque Country and in our study, with over $50 \%$ of LGMD cases (59.26 and $61.29 \%$, respectively). Both studies detected a high frequency of the c.2362_2363delinsAG/TCATCT mutation in exon 22 of the CAPN3 gene, which has been observed primarily in chromosomes of Basque natives and more exceptionally in individuals from other parts of the world [17]. In our study, this pathogenic variant is present in $100 \%$ of the LGMD2A.
The prevalence of dystrophinopathies in our study is 0.94/100,000 for DMD and 0.78/100,000 for BMD. These values are lower than those reported elsewhere. The meta-analysis conducted by Mah et al. [47] showed an estimated prevalence of 4.78/100,000 (CI 95\%; $1.94-$ 11.81) for DMD and 1.53/100,000 (CI 95\%; 0.26-8.94) for BMD. The study performed in New Zealand [5] shows a prevalence of DMD of 2.45/100,000 (CI 95\%; $2.01-2.98$ ) and $1.67 / 100,000$ (CI 95\%; 1.32-2.12) for BMD with ethnic differences. However, some studies

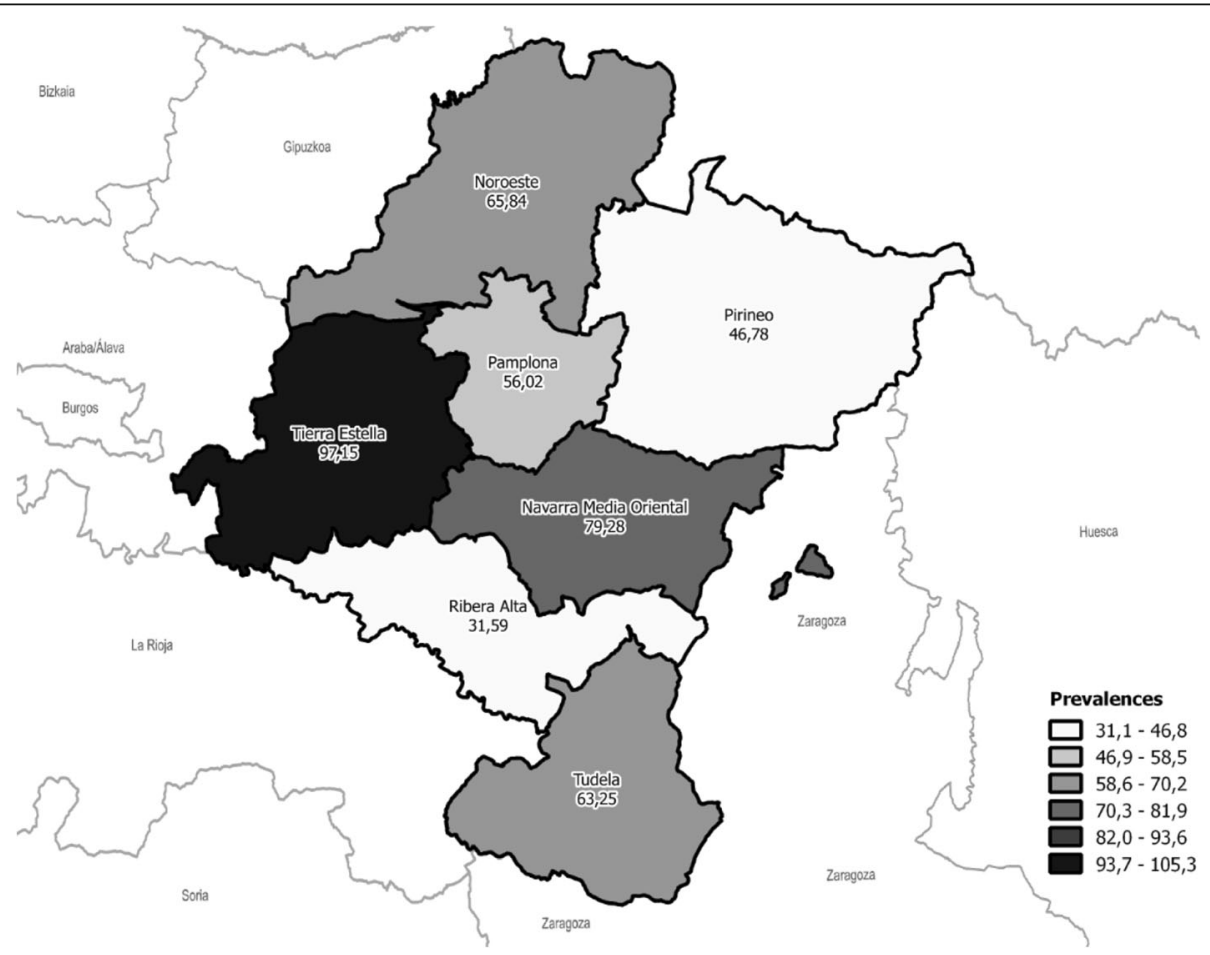

Fig. 3 Geographical distribution of prevalence (per 100,000) of inherited muscle disease in Navarre 
show a prevalence of DMD below 2/100,000 [43, 48]. We believe that the poor exploitation of electronic clinical records from Paediatric Services did not cause a biased estimation of dystrophinopathies in our study.

We observed higher prevalence of IMDs in men than in women. This difference could be due to the X-linked inheritance of DMD and BMD. However, we also observed significant differences in the congenital myopathies subgroup, with higher prevalence in men. Furthermore, there was higher prevalence in men in the following age groups: under 15,25 to 34 , and 75 to 84 years of age. In the under 15 group, the X-linked nature of DMD could explain this elevated prevalence [49]. In the other two age groups, the IMD subtypes differ greatly and we have clear explanation for the gender differences. The highest prevalence of IMDs is seen for the working age group (between 35 to 64 years) probably contributing to huge socio-economic burden. Further studies should be designed to analyse the impact these conditions have on the economy.

We also detected prevalence geographical distribution differences within Navarre, which may be useful when planning resources. The highest prevalence of IMDs was determined for Tierra Estella Area (PR 97.15 with IC 95\% 70.19-134.50) (Fig. 3).

\section{Unclassified inherited muscle disease}

In the course of this study, we identified 49 patients $(9.55 \%)$ with a potential genetic cause for their muscle disease. During the period of our study (2000 to 2015), most genetic diagnosis followed the gene-by-gene testing strategy based on their phenotype. Current availability of next-generation sequencing is changing the diagnostic approach, increasing confirmed genetic diagnosis, as well as the identification of new IMD-associated mutations.

Thirty-nine patients remained alive by the end of the study (December 2015) and from the end of the study to the present time genetic IMD confirmation was obtained for $18(46,15 \%)$.

\section{Study limitations}

Although the study has been exhaustive, poor exploitation of the electronic clinical records in Paediatric Services could bias childhood IMD data, e.g., DMD. However, we believe that the exploitation of other data sources counteracts this deficiency, consequently with mild underestimation of IMD prevalence in this age group.

\section{Conclusions}

The prevalence of IMDs in Navarre is 59.00/100,000 inhabitants CI (53.35-65.26), which is a high number if compared with data reported for other geographical regions. If only patients with confirmed genetic diagnosis are considered, the prevalence is $50.10 / 100,000$ (CI 95\%; 44.92-55.89). The high prevalence of DM-1 (35.90/100, 000 with CI 31.55-40.85) and of LGMD2A (2.5/100,000 with CI 1.54-4.05) could suggest the existence of a founding effect in Navarre. Genetic confirmation was available in $442(86.16 \%)$ of IMD patients in our region. Our population study has a high sensitivity because all possible sources of information have been used. The lack of specificity of disease coding in our health information system for IMDs has made the study difficult and has forced us to review the clinical data of each case to verify the diagnosis. It is essential to implement specific population based registries for neuromuscular and other rare diseases, taking into account the heterogeneity of these disorders.

\section{Abbreviations}

BMD: Becker Muscular Dystrophy; CMD: Congenital Muscular Dystrophy; DM1: Myotonic Dystrophy type 1; DMD: Duchenne Muscular Dystrophy; FSHD: Facioscapulohumeral Dystrophy; ICD: International Classification of Diseases; IMDs: Inherited Muscle Diseases; LGMD: Limb Girdle Muscular Dystrophy

\section{Acknowledgements}

The authors would like to thank all those responsible of the case ascertainment sources consulted for their collaboration; to María A. RamosArroyo and Eva Ardanaz for their kind advices; to the Genetic Department of the Sant Pau Hospital (Barcelona) and the Biodonostia Institute for their collaboration in genetic analysis.

\section{Authors' contributions}

Conceptualization and design: IJ, EV and IP; Methodology: IP, EV, BI and IJ; Funding acquisition: IJ and EV; Data curation: IP, EV, LT, FG, IEB and JD; Map design: JD; Supervision: IJ, EV and Bl; writing-original draft: IP and IJ. All authors read and approved the final manuscript.

\section{Funding}

This study was partially supported by the Health Department of the Navarre Government (project 007-2017), co-funded (50\%) by the European Regional Development Fund (ERDF) through the Navarre ERDF 2014-2020 Operative Programme

\section{Availability of data and materials}

The data that support the findings of this study are available in the records of the health systems described in the study, but restrictions apply to the availability of these data, which were used under license for the current study, and so are not publicly available. Data are however available from the authors upon reasonable request and with permission of Complejo Hospitalario de Navarra and Navarra's Public Health System.

Ethics approval and consent to participate

The study protocol was approved by the Navarre Ethical Committee for Medical Research (Pyto 2016/31)

Consent for publication

Not applicable.

\section{Competing interests}

The authors declare that they have no competing interests.

\section{Author details}

${ }^{1}$ Department of Neurology, Complejo Hospitalario de Navarra, IdiSNA (Navarre Institute for Health Research), Pamplona, Spain. ${ }^{2}$ Community Health Observatory Section, Instituto de Salud Pública y Laboral de Navarra, IdiSNA, Pamplona, Spain. ${ }^{3}$ Department of Health Sciences, Universidad Pública de Navarra (UPNA), IdiSNA, Pamplona, Spain. ${ }^{4}$ Methodology Unit.

Navarrabiomed, Universidad Pública de Navarra (UPNA), IdiSNA, Pamplona, 
Spain. ${ }^{5}$ Primary Care, Servicio Navarro de Salud - Osasunbidea, IdiSNA, Pamplona, Spain. ${ }^{6}$ Miguel Servet Foundation, Navarrabiomed, Pamplona, Spain. 'Department of Genetics, Complejo Hospitalario de Navarra, IdiSNA, Pamplona, Spain. ${ }^{8} \mathrm{CIBER}$ Epidemiology and Public Health (CIBERESP), Madrid, Spain. ${ }^{9}$ Department of Neurology, Complejo Hospitalario de Navarra, 31008 Pamplona, C/ Irunlarrea, Spain.

\section{Received: 19 March 2019 Accepted: 10 October 2019}

\section{Published online: 02 December 2019}

\section{References}

1. Mercuri E, Muntoni F. Muscular dystrophies. Lancet. 2013;381:845-60.

2. D'Angelo MG, Bresolin N. Report of the 95th European neuromuscular Centre (ENMC) sponsored international workshop cognitive impairment in neuromuscular disorders, Naarden, the Netherlands, 13-15 July 2001. Neuromuscul Disord. 2003;13:72-9.

3. Boyer F, Drame M, Morrone I, Novella J-L. Factors relating to carer burden for families of persons with muscular dystrophy. J Rehabil Med. 2006:38:309-15.

4. Lefter S, Hardiman O, Ryan AM. A population-based epidemiologic study of adult neuromuscular disease in the Republic of Ireland. Neurology. 2017;88:304-13.

5. Theadom A, Rodrigues M, Poke G, O'Grady G, Love D, Hammond-Tooke G, et al. A Nationwide, population-based prevalence study of genetic muscle disorders. Neuroepidemiology. 2019;52:128-35.

6. Norwood FLM, Harling C, Chinnery PF, Eagle M, Bushby K, Straub V. Prevalence of genetic muscle disease in northern England: in-depth analysis of a muscle clinic population. Brain. 2009;132:3175-86.

7. Hughes MI, Hicks EM, Nevin NCPV. The prevalence of inherited neuromuscular disease in Northern Ireland. Neuromuscul Disord. 1996;6:69-73.

8. Araki S, Uchino M, Kumamoto T. Prevalence studies of multiple sclerosis, myasthenia gravis, and myopathies in Kumamoto district. Japan Neuroepidemiology. 1987:6:120-9.

9. Darin N, Tulinius M. Neuromuscular disorders in childhood: a descriptive epidemiological study from western Sweden. Neuromuscul Disord. 2000; 10:1-9.

10. Chung B, Wong V, Ip P. Prevalence of neuromuscular diseases in Chinese children: a study in southern China. J Child Neurol. 2003;18:217-9.

11. El-Tallawy HN, Khedr EM, Qayed MH, Helliwell TR, Kamel NF. Epidemiological study of muscular disorders in Assiut. Egypt Neuroepidemiology. 2005;25:205-11.

12. Tangsrud SE, Halvorsen S. Child neuromuscular disease in southern Norway. Prevalence, age and distribution of diagnosis with special reference to "non-Duchenne muscular dystrophy". Clin Genet. 1988;34(3):145-52.

13. Kurtzke JF. Neuroepidemiology. Ann Neurol. 1984;16:265-77.

14. Ahlström $G$, Gunnarsson LG, Leissner P, Sjödén PO. Epidemiology of neuromuscular diseases, including the postpolio sequelae, in a Swedish county. Neuroepidemiology. 1993;12:262-9.

15. Theadom A, Rodrigues M, Roxburgh R, Balalla S, Higgins C, Bhattacharjee R, et al. Prevalence of muscular dystrophies: a systematic literature review. Neuroepidemiology. 2014;43:259-68.

16. López de Munain A, Blanco A, Emparanza Jl, Poza JJ, Martí Massó JF, Cobo A, et al. Prevalence of myotonic dystrophy in Guipúzcoa (Basque Country, Spain). Neurology. 1993;43:1573-6.

17. Urtasun M, Sáenz A, Roudaut C, Poza JJ, Urtizberea JA, Cobo AM, et al. Limb-girdle muscular dystrophy in Guipúzcoa (Basque Country, Spain). Brain. 1998;121:1735-47.

18. Burcet J, Cañellas F, Cavaller G, Vich M. Epidemiologic study of myotonic dystrophy on the island of Mallorca. Neurologia. 1992;7:61-4.

19. Arpa J, Cruz-Martínez A, Campos Y, Gutiérrez-Molina M, García-Rio F, PérezConde C, et al. Prevalence and progression of mitochondrial diseases: a study of 50 patients. Muscle Nerve. 2003;28:690-5.

20. Statistics Navarre 2016 Census. https://administracionelectronica.navarra.es/ GN.InstitutoEstadistica.Web/informacionestadistica.aspx?R=1\&E=1. Accessed 1 Jun 2018.

21. Ministerio de Sanidad y Consumo. Encuesta Nacional de Salud 2011-2012. https:/www.navarra.es/home_es/Temas/Portal+de+la+Salud/Profesionales/ Informacion+tecnica/Sanidad/encuesta+de+salud.htm. Accessed 1 Jun 2018.

22. European data portal. Zonificación Navarra. 2000 https://www. europeandataportal.eu/data/en/dataset/spasitnaestadi_pol_szonnav2000xml01. Accessed 1 Jun 2018.
23. Bonne $G$, Rivier F, Hamroun D. The 2018 version of the gene table of monogenic neuromuscular disorders (nuclear genome). Neuromuscul Disord. 2017;27:1152-83.

24. Harris E, Laval S, Hudson J, Barresi R, De Waele L, Straub V, et al. Undiagnosed genetic muscle disease in the north of England: an in depth phenotype analysis. PLoS Curr. 2013;5.

25. Bönnemann CG, Wang CH, Quijano-Roy S, Deconinck N, Bertini E, Ferreiro A, et al. Diagnostic approach to the congenital muscular dystrophies. Neuromuscul Disord. 2014;24:289-311.

26. MCARDLE B. Myopathy due to a defect in muscle glycogen breakdown. Clin Sci. 1951;10:13-35.

27. Jungbluth H, Sewry CA, Muntoni F. Core myopathies. Semin Pediatr Neurol. 2011;18:239-49.

28. Bornemann A, Goebel HH. Congenital myopathies. Brain Pathol. 2001;11:206-17.

29. Tajsharghi $H$, Thornell L-E, Lindberg C, Lindvall B, Henriksson K-G, Oldfors A. Myosin storage myopathy associated with a heterozygous missense mutation in MYH7. Ann Neurol. 2003:54:494-500.

30. Wallgren-Pettersson C, Sewry CA, Nowak KJ, Laing NG. Nemaline myopathies. Semin Pediatr Neurol. 2011:18:230-8.

31. Clarke NF, North KN. Congenital fiber type disproportion--30 years on. J Neuropathol Exp Neurol. 2003:62:977-89.

32. Udd B. Distal myopathies. Curr Neurol Neurosci Rep. 2014;14:434.

33. Lemmers RJ, van der Vliet PJ, Klooster R, Sacconi S, Camaño P, Dauwerse JG, et al. A unifying genetic model for facioscapulohumeral muscular dystrophy. Science. 2010;329(5999):1650-3.

34. Fernández-Navarro P, López-Abente G, Salido-Campos C, Sanz-Anquela JM. The minimum basic data set (MBDS) as a tool for cancer epidemiological surveillance. Eur J Intern Med. 2016;34:94-7.

35. Esteban-Vasallo MD, Domínguez-Berjón MF, Astray-Mochales J, GènovaMaleras R, Pérez-Sania A, Sánchez-Perruca L, et al. Epidemiological usefulness of population-based electronic clinical records in primary care: estimation of the prevalence of chronic diseases. Fam Pract. 2009. 26:445-54.

36. Ancín Ducay J, Erce López S, Extramiana Cameno E, lzcue Argandoña A. Correlación de códigos CEI-9-MC (8 ${ }^{\mathrm{a}}$ edic) - CIAP-2 para la gestión de Incapacidad Teporal. Inst Salud Pública y Labor Navarra. 2014; https://www. navarra.es/NR/rdonlyres/E520399C-0612-4C75-A912-B16295014FC3/281429/ codigosCIE_9 MC.pdf. Accessed 1 Jun 2018.

37. Kinsner-Ovaskainen A, Lanzoni M, Garne E, Loane M, Morris J, Neville A, et al. A sustainable solution for the activities of the European network for surveillance of congenital anomalies: EUROCAT as part of the EU platform on rare diseases registration. Eur J Med Genet. 2018;61:513-7.

38. Floristán Floristán Y, Delfrade Osinaga J, Carrillo Prieto J, Aguirre Perez J, Moreno-lribas C. Coding causes of death with IRIS software. Impact in Navarre mortality statistic. Rev Esp Salud Publica. 2016;90:e1-9.

39. Gómez-Redondo R, Faus-Bertomeu A, Poniakina S, Cámara-Izquierdo N. About Spain data on causes of death. 2017. https://www.causesofdeath.org/ Data/ESP/20170126/ESP_bd.pdf. Accessed 1 Jun 2018.

40. Estadísticas epidemiológicas de código abierto para Salud Pública. Versión 3.01. http://www.openepi.com/Menu/OE_Menu.htm. Accessed 1 Jun 2018.

41. Yates JR, Emery AE. A population study of adult onset limb-girdle muscular dystrophy. J Med Genet. 1985;22:250-7.

42. Merlini L, Stagni SB, Marri E, Granata C. Epidemiology of neuromuscular disorders in the under-20 population in Bologna Province. Italy Neuromuscul Disord. 1992;2:197-200.

43. Ballo R, Viljoen D, Beighton P. Duchenne and Becker muscular dystrophy prevalence in South Africa and molecular findings in 128 persons affected. S Afr Med J. 1994;84:494-7.

44. Emery AE. Population frequencies of inherited neuromuscular diseases-a world survey. Neuromuscul Disord. 1991;1:19-29.

45. Mathieu J, Prévost C. Epidemiological surveillance of myotonic dystrophy type 1: a 25-year population-based study. Neuromuscul Disord. 2012;22:974-9.

46. Fardeau M, Hillaire D, Mignard C, Feingold N, Feingold J, Mignard D, et al. Juvenile limb-girdle muscular dystrophy. Clinical, histopathological and genetic data from a small community living in the Reunion Island. Brain. 1996;119:295-308.

47. Mah JK, Korngut L, Dykeman J, Day L, Pringsheim T, Jette N. A systematic review and meta-analysis on the epidemiology of Duchenne 
and Becker muscular dystrophy. Neuromuscul Disord. 2014;24:482-91.

48. Siciliano G, Tessa A, Renna M, Manca ML, Mancuso M, Murri L. Epidemiology of dystrophinopathies in North-West Tuscany: a molecular genetics-based revisitation. Clin Genet. 1999;56:51-8.

49. Birnkrant DJ, Bushby K, Bann CM, Apkon SD, Blackwell A, Brumbaugh D, et al. Diagnosis and management of Duchenne muscular dystrophy, part 1: diagnosis, and neuromuscular, rehabilitation, endocrine, and gastrointestinal and nutritional management. Lancet Neurol. 2018;17(3):251-67.

\section{Publisher's Note}

Springer Nature remains neutral with regard to jurisdictional claims in published maps and institutional affiliations.

Ready to submit your research? Choose BMC and benefit from:

- fast, convenient online submission

- thorough peer review by experienced researchers in your field

- rapid publication on acceptance

- support for research data, including large and complex data types

- gold Open Access which fosters wider collaboration and increased citations

- maximum visibility for your research: over $100 \mathrm{M}$ website views per year

At $\mathrm{BMC}$, research is always in progress.

Learn more biomedcentral.com/submissions 